\title{
Delineation of the selected Cucumis L. species and accessions using leaf architecture characters
}

\author{
LAILANI A. MASUNGSONG ${ }^{1,2, ~}$, MARILYN M. BELARMINO ${ }^{3}$, INOCENCIO E. BUOT JR. ${ }^{1}$ \\ ${ }^{1}$ Plant Biology Division, Institute of Biological Sciences, College of Arts and Sciences, University of the Philippines Los Baños, Laguna, Philippines. \\ Tel.: +63-49-5362807, ‘email : lamasungsong@up.edu.ph \\ ${ }^{2}$ Graduate School, University of the Philippines Los Baños, Laguna, Philippines \\ ${ }^{3}$ Hortanova Research Center, East-West Seed Company, Inc., Lipa City, Batangas, Philippines
}

Manuscript received: 2 November 2018. Revision accepted: 8 February 2019

\begin{abstract}
Masungsong LA, Belarmino MM, Buot IEJr. 2019. Delineation of the selected Cucumis L. species and accessions using leaf architecture characters. Biodiversitas 20: 629-635. Regardless of the several attempts of the early and recent studies to separate the wild species of Cucumis from the cultivated ones, there is still taxonomic confusion brought about by the similarities in morphology of the genus. In a gene bank with so many species and accessions of Cucumis stored, it is appropriate to delineate these numerous accessions to save time and resources as well. This study aims to delineate fifty selected Cucumis accessions based on leaf architecture. Using Unweighted Pair Group Method using Averages (UPGMA) and Euclidean distance coefficient, a cluster analysis for the fifty Cucumis accessions was done. A dendogram with cophenetic coefficient of 0.9606 supported the clustering of the Cucumis species and accessions. At Eucledian distance of 1.5 two major clusters were formed on the basis of secondary vein spacing. Cucumis melo accessions separated from all the remaining accessions of $C$. myriocarpus, $C$. metuliferus, $C$. anguria and $C$. anguria var longaculeatus for having an increasing towards the base secondary vein spacing while the rest have irregular pattern of secondary vein spacing. Further sub-clustering of the remaining accessions comprising four species were delineated on the basis of tertiary vein (C. myriocarpus), tertiary vein angle to primary (C. metuliferus), and blade class (C. anguria and C. anguria var longaculeatus). Laminar shape delineated $C$. myriocarpus accessions from each other, apex angle for $C$. metuliferus accessions, and primary vein size for $C$. melo accessions. Results implied that leaf architecture is a good tool to classify the numerous accessions of Cucumis.
\end{abstract}

Keywords: Cluster analysis, leaf architecture, taxonomic character, taxonomic tool

\section{INTRODUCTION}

Genus Cucumis L. is said to be one of the economically most important genera of flowering plants. Many species and varieties of Cucumis have emerged and being cultivated all over the world because of its economic importance (Wehner and Maynard 2003).Workers on Cucumis species accessions (Cucurbitaceae) experience difficulties in taxonomic identification due to apparent morphological similarities brought about by inherent plasticity of characters when they are subjected to diverse environmental conditions. Early and recent studies failed in separating the cultivated accessions.

Leaves and its traits are often ignored by taxonomists when it comes to identification and classification of plant taxa because these traits have high phenotypic plasticity. Leaf characters, specifically venation patterns are genetically fixed therefore can be used as a taxonomic tool. Leaf venation structure is said to be influenced by its main functions namely, transport of substances, solutes, and hormones through the xylem vessels, and exports of carbohydrates through the phloem and mechanical stabilization based on the lignified and sclerified elements, therefore this relationship can be of great importance for its taxonomic value (Laraño and Buot 2010). Leaf architecture is one of the most important morpho-anatomical tools highly useful in species delineation. Leaves, despite phenotypic plasticity, have genetically-fixed and established venation patterns which are significant when dealing with sterile fossil plants (Roth-Nebelsick et al. 2001). Several studies utilized various leaf characters in identifying and classifying plant taxa. One of such was that of Laraño and Buot (2010) which supported the merging of families Malvaceae, Sterculiaceae, Tiliaceae and Bombacaceae into family Malvaceae as described in the Angiosperm Phylogeny Group (APG) based on DNAsequenced data (APG 1998). Other studies with significant results were on Psychotria species (Banaticla and Buot 2004), Philippine Cinnamomum species (Celadina et al. 2012), Terminalia species (Baroga and Buot 2014), and Hoya species (Salvaña and Buot 2014; Jumawan and Buot 2016; Torrefiel and Buot 2017). All of these studies revealed invaluable results proving the importance of leaf architecture in morphology as well as in taxonomy of controversial taxa.

In the gene bank of Hortanova Farm and Research Center, East-west Seed Inc., several Cucumis accessions are maintained but identities are problematic. There is a need to carry out leaf architectural studies to determine intraspecific variations and delimit the Cucumis species and accessions. To date, there had been no study specifically on Cucumis species leaf architecture that can be used to classify and identify its growing population. This study aims to delineate the selected Cucumis species 
and accessions using leaf architecture. Results can be used for breeding purposes and better management of the gene bank.

\section{MATERIALS AND METHODS}

Leaf samples from fifty accessions belonging to five systematically planted Cucumis species were examined in this study namely: i. C. anguria, ii. . C. anguria var. longaculeatus, iii. C. melo, iv. C. metuliferus and v. C. myriocarpus (Table 1). Three fully expanded leaves from three standing crops of each accessions were collected at the Hortanova Farm and Research Center, East-west Seed Inc., Lipa City, Batangas, Philippines. A total of four hundred fifty collected leaf samples were pressed, dried, and examined under a dissecting microscope. The leaf architecture pattern of the leaf samples was described based on Hickey's (1973), LAWG's (1999) and Ellis' et al. (2009) leaf architectural characteristics and descriptors. Measurements were done using a ruler, a caliper, and a protractor. Eleven (11) general leaf and vein characters were used in examining the collected leaf samples. Leaf characters include: (1) blade class, (2) laminar shape, (3) laminar symmetry, (4) length-width ratio, (5) apex shape, (6) apex angle, (7) base shape, (8) base angle, (9) margin, (10) tooth apex and (11) lobation. Vein characters include primary vein (category, size, course), secondary vein (category, spacing, angle), tertiary vein (category, angle in relation to primary vein), quaternary vein category, marginal ultimate venation and areole development. Blade class was determined by measuring the area of the leaf and values were categorized based on leaf classes established by Webb (1955). Categories include leptophyll, nanophyll, microphyll, notophyll, mesophyll, macrophyll and megaphyll. Laminar shape was determined by locating the axis or the zone of the greatest width that lies perpendicular to the axis of greatest length. The proportion of the left and right side of the lamina with reference to the location of the midvein was the laminar symmetry. Length and width of the leaf was measured to determine length-width ratio. The angle from the apical termination of the midvein to the pair of points where a line perpendicular to the midvein and $0.75 l_{m}$ from the base intersect the margin was measured to determine apex angle. On the other hand, base angle is measured from the vertex to the points where a line perpendicular to the midvein at $0.25 l_{m}$ from the base intersects the margin. Other characters such as, apex shape, base shape, margin, tooth apex and lobation were determined by comparing samples with established categories of these characters.

Comparison and measurements were carried out to determine vein characters. Vein measurements were done using a ruler and a caliper while angle of divergence was measured using a protractor. Vein category, either primary, secondary, tertiary and quaternary, was determined by comparing samples with leaf architecture manual with reference to the orientation of each vein orders and anastomosing patterns. Vein course was determined by examining noticeable curvatures and ramifications which can be straight (branched, unbranched), markedly curved, sinuous and zigzag. Vein angle was determined by measuring the branch of each vein and the continuation of the source vein above the point of branching. The midway between the leaf apex and base as to the ratio of the vein width and leaf with was the basis in determining primary vein size. Secondary vein spacing was determined by examining the spaces of the secondary veins from apex to base which can either be uniform, irregular, decreasing or increasing towards the base. Tertiary angle was measured with reference to its orientation to the primary vein. Ultimate marginal venation was determined by examining free ending veinlets and loops at the leaf margin. The appearance and characteristic of the areoles were based on areolation. Classification of areole development was determined by examining veinlets crosses in the areoles. These vein characters and patterns were sketched. Line drawings were done using Adobe Photoshop CS6 v.13.1.2 based from photos captured by Nikon D3100 (Tamron $90 \mathrm{~mm} \mathrm{f} / 2.8$ SP AF Di Macro 1: 1 lens). The leaf architecture characters generated for the fifty Cucumis accessions were used to determine its species and accessions delineation. Cluster analysis was done using PAleontological STatistics (PAST) version 3.11 and a dendrogram was constructed using Euclidean distance and Unweighted Pair-group Method using Averages or UPGMA as linkage method. A total of twenty one leaf characters were selected and each of the character state was assigned a value corresponding to a legend as follows: Blade class (BC) (1- Mesophyll; 2- Notophyll); Laminar shape (LSP) (1- orbiculate; 2- sub-orbiculate); Laminar symmetry (LSY) (1- symmetrical); Primary vein category (PVC) (1-actinodromous suprabasal); Primary Vein Size (PVZ) (1- stout; 2- moderate; 3- weak); Primary Vein Course (PVCo) (1- straight branched); Secondary vein category (SVC) (1- craspedodromous); Secondary vein angle category (SVAC) (1-two pair acute basal secondaries); Tertiary vein angle to primary (TVAP) (1obtuse; 2- acute); Tertiary vein angle (TVC) (alternate percurrent; 2- random reticulate); Quaternary vein angle (QVC) (1-regular polygonal reticulate); Apex angle (AA) (1- obtuse; 2- acute; 3- odd-lobed obtuse; 4- odd-lobed acute); Margin (M) (1- serrate); Lobation (Lo) (1-palmately lobed; 2- unlobed); Marginal Ultimate Venation (MUV) (1looped); Areole development (AD) (1-well-developed; 2moderately developed); Secondary vein spacing (SVS) (1increasing towards the base; 2- irregular); Base angle (BA) (1- wide obtuse); Apex shape (AS) (1- convex); Base shape (BS) (1-lobate); and Tooth apex (TA) (1- spinose).

\section{RESULTS AND DISCUSSION}

The fifty accessions from the five Cucumis L. species examined in this study had great similarities in terms of leaf morphological features. In general, Cucumis had simple leaf, elliptic in shape and with distinct serrations at margins. They usually had palmately lobed leaves with convex apex, lobate base and spinose tooth apex. 
Table 1. Details of the Cucumis species used in the study

\begin{tabular}{|c|c|c|c|}
\hline Scientific name & $\begin{array}{l}\text { Type of } \\
\text { material }\end{array}$ & Place of origin & $\begin{array}{c}\text { Accession } \\
\text { number }\end{array}$ \\
\hline \multirow{10}{*}{ Cucumis melo } & Cultivated & Senegal & GB-000367 \\
\hline & land race & Afghanistan & GB-000331 \\
\hline & land race & Mandalay & GB-000330 \\
\hline & land race & Zambia & GB-000389 \\
\hline & land race & Ecuador & GB-000359 \\
\hline & No data & No data & GB-000318 \\
\hline & No data & No data & GB-000366 \\
\hline & land race & India & GB-000113 \\
\hline & land race & China & GB-000263 \\
\hline & Uncertain & Dominican Rep. & GB-000338 \\
\hline \multirow{11}{*}{$\begin{array}{l}\text { Cucumis } \\
\text { myriocarpus }\end{array}$} & & & \\
\hline & Wild & South Africa & GB-000407 \\
\hline & No data & No data & GB-000635 \\
\hline & Wild & South Africa & GB-000411 \\
\hline & Wild & South Africa & GB-000409 \\
\hline & Wild & Zimbabwe & GB-000413 \\
\hline & Wild & Australia & GB-000404 \\
\hline & Wild & South Africa & GB-000408 \\
\hline & Wild & Zimbabwe & GB-000414 \\
\hline & Wild & South Africa & GB-000412 \\
\hline & Wild & South Africa & GB-000406 \\
\hline \multirow[t]{10}{*}{ Cucumis anguria } & Wild & Mexico & GB-000545 \\
\hline & Wild & Zimbabwe & GB- 000550 \\
\hline & Wild & Iran & GB-000532 \\
\hline & Wild & Zimbabwe & GB-000547 \\
\hline & Wild & Zimbabwe & GB-000548 \\
\hline & Wild & No data & GB-000062 \\
\hline & Wild & Zimbabwe & GB-000546 \\
\hline & Wild & Zimbabwe & GB-000530 \\
\hline & Wild & Ethiopia & GB-000531 \\
\hline & Wild & Zimbabwe & GB-000554 \\
\hline \multirow{10}{*}{$\begin{array}{l}\text { Cucumis } \\
\text { metuliferus }\end{array}$} & & & \\
\hline & Wild & Zimbabwe & $\begin{array}{l}\text { GB-000624 } \\
\text { GB-000627 }\end{array}$ \\
\hline & Cultivated & Zambia & GB-000632 \\
\hline & Cultivated & Zambia & GB-000631 \\
\hline & Wild & South Africa & GB-000618 \\
\hline & Uncertain & $\begin{array}{l}\text { Soviet Union, } \\
\text { former }\end{array}$ & GB-000621 \\
\hline & Cultivated & Netherlands & GB-000620 \\
\hline & land race & South Africa & GB-000619 \\
\hline & Wild & Netherlands & GB-000622 \\
\hline & Cultivated & Zimbabwe & GB-000625 \\
\hline \multirow{10}{*}{$\begin{array}{l}\text { Cucumis anguria } \\
\text { var longaculeatus }\end{array}$} & & & \\
\hline & Wild & Zambia & GB-000568 \\
\hline & Wild & South Africa & GB-000559 \\
\hline & Wild & South Africa & GB-000558 \\
\hline & Wild & Zambia & GB-000567 \\
\hline & Cultivated & Namibia & GB-000565 \\
\hline & Cultivated & Zambia & GB- 000570 \\
\hline & Cultivated & Zambia & GB-000569 \\
\hline & Wild & Brazil & GB-000562 \\
\hline & Wild & Zimbabwe & GB-000571 \\
\hline
\end{tabular}

In terms of venation patterns, Cucumis had craspedodromous $2^{\circ}$ veins, alternate percurrent $3^{\circ}$ veins and regular polygonal reticulate $4^{\circ}$ veins. They had actinodromous suprabasal $1^{\circ}$ veins, and looped marginal ultimate venation. Venation characters and patterns of each species are shown in Figure 1. Variations in leaf venation patterns are valuable in identifying taxonomic group, differentiating species and even delineation of different accessions and/or varieties (Badron et al. 2014). All of the fifty Cucumis accessions studied have reached at least $4^{\circ}$ vein order which according to Sack and Scoffoni (2013), should have achieved maximum rate of water transport, which can be correlated to maximum rate of photosynthesis achieved. In addition, they can also provide cost-efficiency for biomechanical support and protection against damage cause by insects and herbivores. In the leaf architectural study conducted by Rao et al. (2015) in some members of family Cucurbitaceae, they have also observed some of these leaf characters in the representative species of Cucumis.

There were notable leaf architectural features that unify and distinguish different accessions of five Cucumis L. species. Accessions of $C$. myriocarpus were distinguished based on laminar shape. Most accessions have orbiculate laminar shape while one accession, GB 000406, had suborbiculate laminar shape. Moreover, similarity of $C$. anguria accessions was observed in blade class wherein most accessions belong to notophyll blade class. Surprisingly, two accessions of this species, GB 000062 and GB 000554, shared similar blade class category with all accessions of $C$. anguria var longaculeatus which is mesophyll. Accessions of $C$. metuliferus were distinguished based on apex angle. Six accessions, GB 000624, GB000627, GB 000618, GB 000619, GB 000632, GB 000631, have odd-lobed acute angle while four accessions, GB 000625, GB 000620, GB 000621, GB 000622, have odd-lobed obtuse apex angle. Primary vein size distinguished the accessions of $C$. melo. Nine accessions have weak primary vein size while three accessions have moderate primary vein size. This unifying and distinguishing leaf architectural features was supported by the result of the cluster analysis as shown in Figure 2.

Based on the result of the cluster analysis using Unweighted Pair Group Method using Averages (UPGMA) and Euclidean distance coefficient, different accessions of different species of Cucumis examined in this study formed two main clusters based on the secondary vein spacing (Figure 2). Cluster 1 includes all accessions of $C$. melo separated from other accessions of other species as they exhibit secondary vein spacing increasing towards the base. Cluster 2 includes all accessions of $C$. myriocarpus, $C$. metuliferus, $C$. anguria and $C$. anguria var longaculeatus with irregular secondary vein spacing. Secondary vein spacing is related to lobation. Palmately lobed species have smaller surface area compared to unlobed species. Also, leaf lobes were noted to be essential to discriminate specific vein patterns and can display accurate homological and/or ancestral relationships (Viscosi and Cardini 2011; Inamdar and Shenoy 1982). Lobation and primary vein size were also some of the leaf characters served as basis for classifying the bilobate leaf fossils and evaluating the fossil record and biogeography of Bauhinia species (Lin et al. 2015). It was observed that accessions with irregular secondary vein spacing were unlobed while those that have secondary vein spacing increasing towards the base were palmately lobed. Secondary veins were noted to act as support system of the lamina. 
One of the striking features of vascular pattern is spatial regularity of leaf veins especially in advanced dicots and monocots. This regularity is also apparent in the reticulate venation of dicots despite of the differences in leaf shape. Considering the regularity of this leaf vein character, it is considered as a strong character in delineating taxonomic groups. Differences can be seen in the uniformity of the veins which can either be primary, secondary, tertiary or higher vein orders (Nelson and Dengler 1997). The spacing represents the strength of the support. In palmately lobed leaves, shorter secondary vein space was needed to support the lobed part as it was far from the midvein and petiole. Increasing secondary vein spacing towards the base implies that the support was provided by the petiole.

Six subclusters were also observed from Cluster 1 . In $C$. myriocarpus, Subcluster 1a includes accessions with orbiculate laminar shape while Subcluster 1b, with only one accession (GB 000406), had sub-orbiculate laminar shape. Both orbiculate and sub-orbiculate were classified under elliptic laminar shape. This can be determined based on the length and width ratio of the lamina. Hickey (1973) stated that one of the fundamental characters used to describe a particular species is laminar shape. A qualitative range of this character was used since variations may exist as it was affected by environmental variables. Nevertheless, it is commonly used in identifying unknown species. Variabilities of laminar shape are commonly observed among species of some genera which were used to classify these species (Bhat 1995). Laminar shape can be associated to leaf surface area since it was determined by getting the length and width ratio of the lamina. It was one of the most easily recognized character in comparing and delineating interspecific and intraspecific taxa (Kpadehyea and Buot 2014).

Subcluster 1c includes accessions of $C$. anguria with notophyll blade class, however, two accessions (GB 000062, GB 000554) formed cluster (Subcluster 1d) with all accessions of $C$. anguria var longaculeatus having mesophyll blade class. All accession of these two species exhibit odd-lobed obtuse apex angle. Cucumis anguria accessions, GB 000062 and GB 000554, were more likely to be of same species as that of $C$. anguria var longaculeatus based on this similarity. Blade class was categorized based on the surface area of the leaf. Mesophyll leaves have larger surface area compared to notophyll leaves. As a high-value crop, blade classes of Cucumis can be used as a commercial tool in identifying different accessions since this character was used in the classification of accessions like in Glycine max (Chen and Nelson 2004). Blade class was also used in splitting and separating species in a specific genus and infraspecific taxa (Baroga and Buot 2014; Kpadehyea and Buot 2014; Borazan and Babac 2003). This character was also used in clarifying controversial lumping of species (Laraño and Buot 2010).

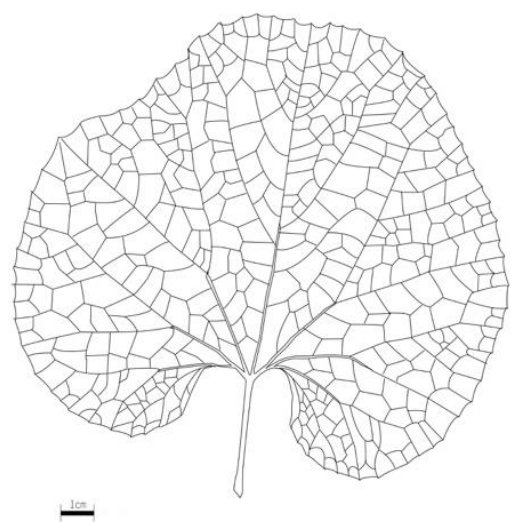

A

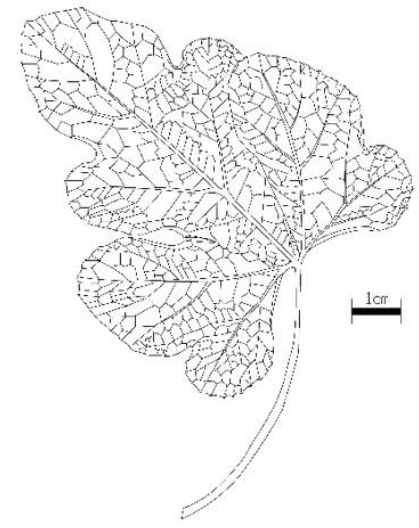

B

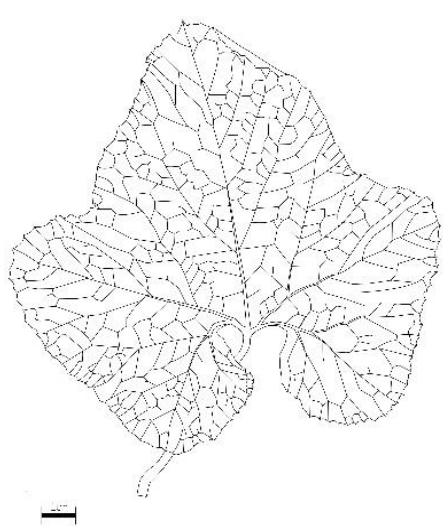

C

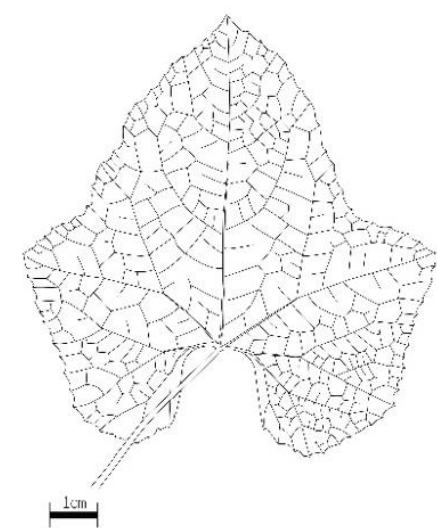

D

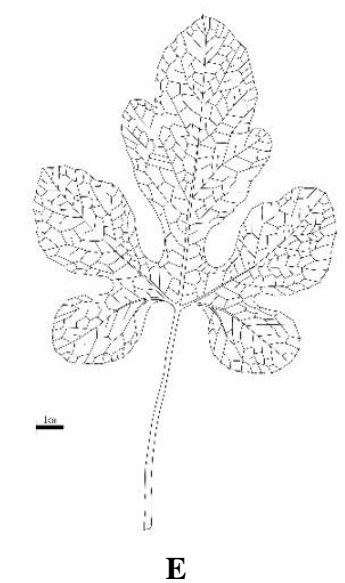

Figure 1. Vein characters and patterns of five Cucumis species: A. C. melo, B. C. myriocarpus, C. C. anguria, D. C. metuliferus, and E. C. anguria var. longaculeatus 
In $C$. metuliferus, Subcluster 1e includes accessions (GB-000624, GB-000627, GB-000618 and GB-000619) with odd-lobed acute apex angle while Subcluster $1 \mathrm{f}$ accessions (GB-000625, GB-000621, GB-000620 and GB000622) have odd-lobed obtuse apex angle. Apex angle in odd-lobed leaves represents the degree of lobation. Oddlobed acute leaves have prominent lobation compared to odd-lobed obtuse leaves. It was also observed that the prominence of lobation was associated to surface area. Thus, apex angle and lobation are associated to leaf shape. Apex angle together with other measurements are part of numerical taxonomic approaches used to describe species. This provides numerical values which have corresponding qualitative characters. Measurements are more or less definite, thus, classifying and identifying species based on apex angle are reliable (Hill 1980; Nandyal et al. 2013).

Two subclusters formed from Cluster 2 which includes all accessions of $C$. melo. Subcluster 2 a includes accession with weak primary vein size while Subcluster $2 b$, with three accessions namely, GB-000367, GB-000318 and control (DIOSA), have moderate primary vein size. Primary vein size can be associated to leaf size. Accessions with weak primary vein size were observed to have small leaf size. Three accessions with moderate primary vein size have larger leaves compared to other accession. Primary vein characteristics are used to described and classify morphologically similar leaves of some species like Podocarpus (Salvaña et al. 2018) and subsections of Anthurium (Mantovani et al. 2009). Moreover, venation patterns are indeed significant features for the classification and even tracing the evolution of angiosperms since these are relatively stable at the species level. As being pointed out by Hickey (1973) and Melville (1976), venation is an important leaf character of a young and mature leaf where its veins and veinlets play a very significant role in taxonomy. Across and within species, leaves are extremely diverse in venation architecture and despite phenotypic plasticity, have genetically-fixed and established venation patterns which are significant when dealing with sterile fossil plants (Roth-Nebelsick et al. 2001). In fact, Oliveira et al. (2017) found that leaf morphology and venation can be used to delineate four problematic species of Psidium namely $P$. firmum, $P$. guineense, $P$. myrsinites and $P$. lamotteanum.

This successful delineation of selected leaf architecture characters using the using cluster analysis were also observed in the works of Loufty et al. (2005) in Ficus L species, Sharma et al. (2016) in Mangifera indica varieties, Oliveira et al. (2017) in Psidium species and Lu et al. (2012) in Camella species. Similarly, studies in Hoya (Salvaña and Buot 2014; Jumawan and Buot 2016; Villareal and Buot 2015; Torrefiel and Buot 2017), Psychotria (Banaticla and Buot 2004), Terminalia (Baroga and Buot 2014), Cinnamomum (Celadiña et al. 2012), and Shorea (Pulan and Buot 2014) proved successful species delineation using leaf architecture. In plant systematics, phenetics is commonly used since it attempts to classify organisms based on their overall similarities (morphological characteristics and observable traits) which serve as basis for making clusters that aid in classification of different plant species (Zhang et al. 2014). The classification is illustrated in a phenetic dendrogram, a treelike scheme or diagram of relationship indicating the affinity of taxa to their nearest relatives on the basis of similarities or phenetic resemblance (Sokal and Rohlf 1962). Most of the studies conducted regarding establishment of species identity and relationships used distance matrices or clustering methods such as Unweighted Pair Group Method using Averages (UPGMA) which can result in accurate estimates of the phylogeny of a group of organisms, thus served as useful techniques for inferring cladistic relationships (Sokal 1986).

In conclusion, the results of this study suggests that the use of leaf architectural characters was successful in delineating different accessions of Cucumis L. species. From all the fifty Cucumis accessions, the ten accessions belonging to $C$. anguria var longaculeatus (GB-000558, GB-000559, GB-000560, GB-000562, GB-000565, GBCHA000567, GB-000568, GB-000569, GB-000570, GB000571) exhibited same leaf characters and were clustered into one. Therefore these accessions were most likely of same species based on leaf architecture. However, two accessions namely GB-000062 and GB-000554 from $C$. anguria shared the same leaf characters and were grouped with the accessions of $C$. anguria var longaculeatus thus, these two accessions can be of the same species as of the latter. Accessions of $C$. anguria (GB-000530, GB-000531, GB-000532, GB-000545, GB-000546, GB-000547, GB000548, GB-000550) which belong to one cluster were most probably of the same species based on the similarities of leaf architectural characters. This clustering pattern due to similar leaf architecture characters was also observed in the accessions of the remaining species such as $C$. myriocarpus (GB-000407, GB-000411, GB-000409, GB000404, GB-000408, GB-000635, GB-000413, GB000414, GB-000412, GB-000406), C. metuliferus (GB000624, GB-000627, GB-000618, GB-000619, GB000632, GB-000631, GB-000625, GB-000620, GB000621, GB-000622) and C. melo ( GB-000331, GB000330, GB-000389, GB-000366, GB-000113, GB000359, GB-000263, GB-000338, GB-000367, GB000318, GB-00062, Diosa) as evidenced in the dendrogram. Distinct clustering of the accessions implies that similarities merit these accessions to be of the same species. The distinct clustering of the Cucumis species and accessions proved that leaf architecture characters were good diagnostic tool in proving the identity and classification of a certain species with numerous accessions in addition to delineating problematic plant taxa. 


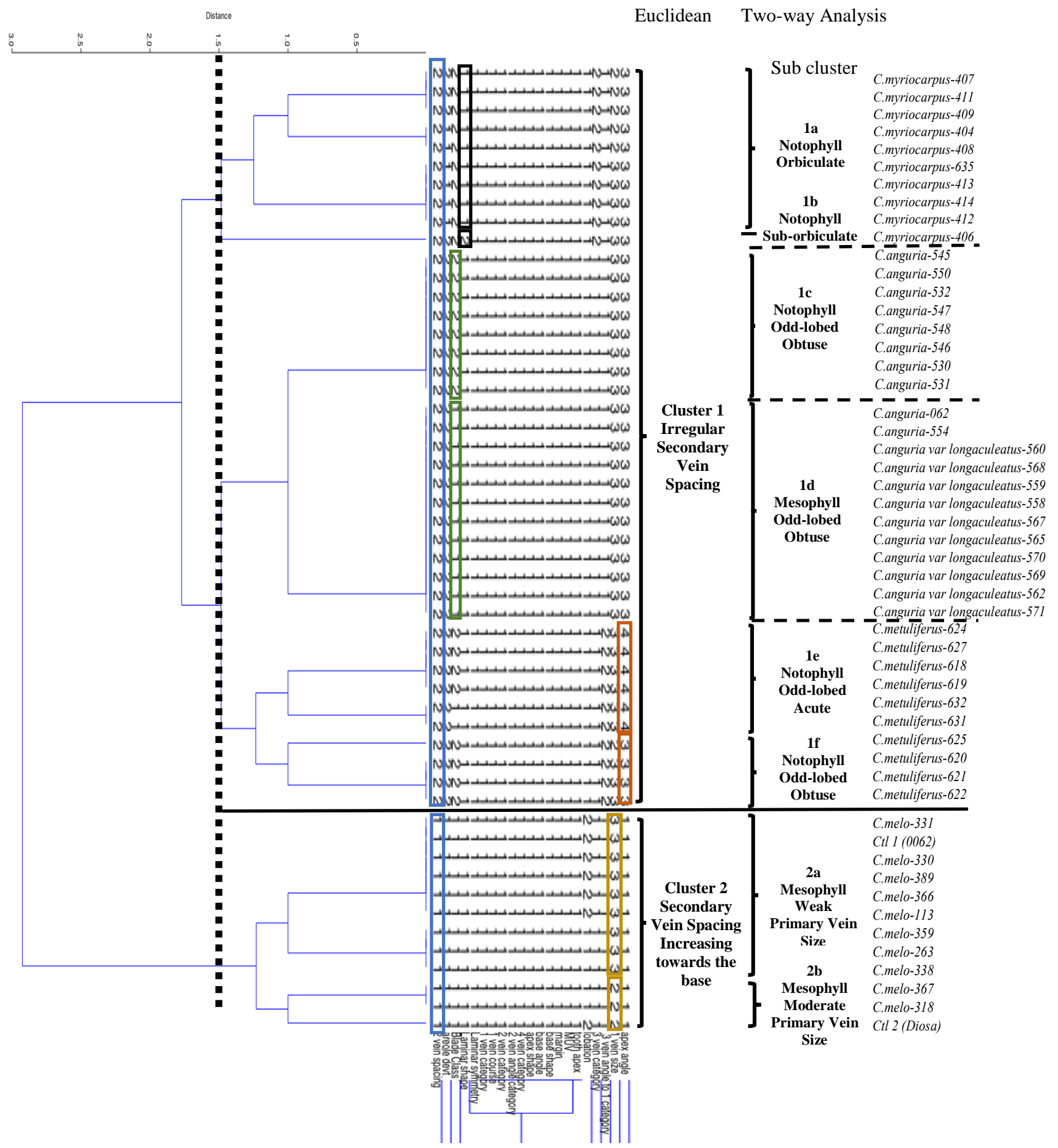

Figure 2. Unweighted Pair Group Method using Averages (UPGMA) dendrogram, based on Euclidean distance coefficient of the accessions of different species of Cucumis showing two main clusters based on secondary vein spacing separating accessions of $C$. melo from other accessions of other species ( $\square$ ) with the Euclidean distance of 1.5; accessions of C. myriocarpus were separated based on laminar shape ( $\mathbf{\square})$; accessions of $C$. anguria formed cluster based on blade class (notophyll), however, some accessions of $C$. anguria (GB-000062 \& GB-000554) formed cluster with accessions of $C$. anguria var. longaculeatus with mesophyll blade class (D); accessions of $C$. metuliferus formed two clusters based on apex angle (ם); and accessions of $C$. melo formed two clusters based on primary vein size (). Cophen. Coeff. 0.9606. 


\section{ACKNOWLEDGEMENTS}

Special thanks to Hortanova Farm and Research Center, East-west Seed Company, Inc. for providing leaf samples and Department of Agriculture-Bureau of Agricultural Research (DA-BAR) and Department of Science and Technology (DOST) for financial support.

\section{REFERENCES}

APG [Angiosperm Phylogeny Group]. 2016. An update of the Angiosperm Phylogeny Group classification for the orders and families of flowering plants: APG IV. Bot J Linn Soc 181: 1-20.

Badron UH, Talip N, Mohamad AL, Affenddi AEA, Juhari AAA. 2014 Studies on leaf venation in selected taxa of the genus Ficus L. (Moraceae) in Peninsular Malaysia. Trop Life Sci Res 25: 111-125.

Banaticla MCN, and Buot Jr IE. 2004. Leaf architecture of ten Philippine Psychotria species (Rubiaceae). Philipp. Scient. 41: 74-90.

Baroga JB, Buot Jr IE. 2014. Leaf architecture of ten species of Philippine Terminalia Linn. (Combretaceae). Int Res J Biol Sci. 3: 83-88.

Bhat RB. 1995. Taxonomic implications of leaf architecture in the genus Hibiscus. S Afr J Bot 61: 209-214.

Borazan A, Babac MT. 2003. Morphometric leaf variation in oaks (Quercus) of Bolu, Turkey. Annales Botanici Fennici 40: 233-242.

Celadiña DA, Buot Jr IE, Madulid DA, Evangelista TT, Tandang DA. 2012. Leaf architecture of selected Philippine Cinnamomum Schaeff. (Lauraceae) species. The Thail Nat His Mus J 6: 89-111.

Chen Y, Nelson RL. 2004. Evaluation and classification of leaflet shape and size in wild soybean. Crop Sci. 44: 671-677.

Conda JM, Buot Jr IE. 2018. Species delineation of the genus Diplazium Swartz (Athryaceae) using leaf architecture characters. Bangladesh Journal of Plant Taxon. 25: 123-133.

Ellis B., Daly DC, Hickey LJ, Johnson KR, Mitchell JD, Wilf P, Wing SL. 2009. Manual of Leaf Architecture. The New York Botanical Garden Press, Ithaca, New York.

Hickey LJ. 1973. Classification of the architecture of dicotyledonous leaves. Am J Bot 60: 17-33.

Hill RS. 1980. A Numerical taxonomic approach to the study of angiosperm leaves. Bot Gaze 141: 213-229.

Inamdar JA, Shenoy KN. 1982. Leaf architecture of Merremia DENNST ex HALL. f. (Convolvulaceae). Flora 172: 96-104.

Jumawan JH, Buot Jr IE. 2016. Numerical taxonomic analysis in leaf architectural traits of some Hoya R. BR. species (Apocynaceae) from Philippines. Bangladesh J. Plant Taxon. 23 (2): 199-207

Laraño AA, Buot Jr IE. 2010. Leaf architecture of selected species of Malvaceae sensu APG and its taxonomic significance. Philipp J Syst Biol 4: 21-54.

Lawren S, Scoffoni C. 2013. Leaf venation: structure, function, development, evolution, ecology and applications in the past, present and future. New Phytol 198: 983-1000.

Leaf Architecture Working Group (LAWG). 1999. Manual of Leaf Architecture Morphological Description and Categorization of Dicotyledonous and Net-veined Monocotyledonous angiosperms. Smithsonian Institute, Washington DC.

Lin Y, Wong WO, Shi G, Shen S, Li Z. 2015. Bilobate leaves of Bauhinia (Leguminosae, Caesalpinioideae, Cercideae) from the middle Miocene of Fujian Province, southeastern China and their biogeographic implications. BMC Evol Biol 15: 252. DOI: 10.1186/s12862-015-0540-9.

Loutfy MHA, Karakish EAK, Khalifa SF, MIRA ERA. 2005. Numerica taxonomic evaluation of leaf architecture of some species of genus Ficus L. Intl J Agri Biol 7: 352-357.

Lu H, Jiang W, Ghiassi M, Lee S, Nitin M. 2012. Classification of Camellia (Theaceae) species using leaf architecture variations and pattern recognition techniques. PLoS One 7: e29704. DOI: 10.1371/journal.pone.0029704.

Mantovani A, Pereira TE, Coelho MAN. 2009. Leaf midrib outline as a diagnostic character for taxonomy in Anthurium section Urospadix subsection Flavescenti viridia (Araceae). Hoehnea 36 (2): 269-277.

Nandyal, SS, Anami BS, Govardhan A. 2013. Base and apex angles and margin types-based identification and classification from medicinal plants' leaves images. Intl J Comput Vis Robotics 3: 197.

Navrátilová B, Skálová D, Ondřej V, Kitner M, Lebeda A. 2011. Biotechnological methods utilized in Cucumis research - A review. Hort Sci (Prague) 38: 150-158.

Nelson T, Dengler N. 1997. Leaf vascular pattern formation. Plant Cell 9: 1121-1135.

Oliveira EF, Bezerraa DG, Santos ML, Rezende MH, Paula JAM. 2017. Leaf morphology and venation of Psidium species from the Brazilian Savanna. Rev Bras de Farmacog 27: 407-413.

Pitrat MP, Hammer H, Hammer K. 2000. Some comments on intraspecific classification of cultivars of melon. Acta Hort 510: 29-36.

Pulan DE, Buot Jr IE. 2014. Leaf architecture of Philippine Shorea species (Dipterocarpaceae). Intl Res J Biol Sci 3: 19-26.

Rao SRS, Rao SS. 2015. Leaf architectural studies in some Cucurbitaceae. J. Indian Bot Soc 94: 64-72.

Sack L, Dietrich EM, Streeter CM, Sanchez-Gomez D, Holbrook NM 2008. Leaf palmate venation and vascular redundancy confer tolerance of hydraulic disruption. Proc Natl Acad Sci USA 105: 15671572

Sack L, Scoffoni S. 2013. Leaf venation: structure, function, development, evolution, ecology and applications in the past, present and future. New Phytol 198 : 983-1000.

Salvaña FRP, Buot Jr IE. 2014. Leaf architectural study of Hoya coriacea, Hoya halconensis and Hoya buotii (Apocynaceae). Intl Res J Biol Sci 3: 37-44.

Salvaña FRP, Gruezo WSm, Hadsall AS. 2018. Recent taxonomic notes and new distribution localities of Podocarpus Pers. species in the Philippines. Sibbaldia: J Bot Garden Hort. 16: 99-120

Sharma B, Albert S, Dhaduk H. 2016. Leaf venation studies of 30 varieties of Mangifera indica L. (Anacardiaceae). J Plant Taxon Geog. 71: 253-263.

Sokal RR, Rohlf FJ. 1962. The comparison of dendrogram by objective methods. Taxon 11: 33-40

Sokal RR. 1986. Phenetic taxonomy: Theory and methods. Ann Rev Ecol Syst 17: 423-42.

Telford IRH, Sebastian P, Bruhl JJ, Renner SS. 2011. Cucumis (Cucurbitaceae) in Australia and eastern Malesia, including newly recognized species and the sister species to C. melo. Syst Bot 36: 376389.

Torrefiel JT, Buot Jr IE. 2017. Hoya carandangiana, Hoya bicolensis, and Hoya camphorifolia (Apocynaceae) species delineation: Insights from leaf architecture. Thail Nat His Mus J 11: 35-44.

Villareal AMM, Buot Jr IE. 2015. Leaf Architecture of Hoya incrassata Warb. and Hoya crassicaulis Elmer x Kloppenb. (Apocynaceae): Taxonomic Identification and conservation concerns. IAMURE Intl J Ecol Conserv 15: 203-213.

Viscosi V, Cardini A. 2011. Leaf morphology, taxonomy and geometric morphometrics: A simplified protocol for beginners. PLoS ONE 6: e25630. DOI: 10.1371/journal.pone.0025630.

Wehner TC, Maynard DN. 2003. Introductory: Cucurbitaceae (Vine Crops). John Wiley \& Sons, Ltd., New York.

Zhang X, Guan T, Zhou J, Cai W, Gao N, Du H, Jiang L, Lai L, Zheng Y. 2018. Community characteristics and leaf stoichiometric traits of desert ecosystems regulated by precipitation and soil in an arid area of China. Intl J Environ Res Public Health 15: 109.

Zhang YQ, Wang XM, Wu AL, Ren Y. 2014. Merging Fargesia dracocephala into Fargesia decurvata (Bambusoideae, Poaceae): Implications from Morphological and ITS Sequence Analyses. PloS One 9: e101362. DOI: 10.1371/journal.pone.0101362. 